\title{
Performance Evaluation of Synthetic-Based Drilling Fluid with Flat Rheology
}

\author{
Tie Geng ${ }^{1,2, ~ *}$, Zhengsong Qiu ${ }^{1}$, Hailong Miao $^{2}$, Wei Zhang ${ }^{2}, \mathrm{Ke} \mathrm{Lei}^{2}$ \\ ${ }^{1}$ School of Petroleum Engineering, China University of Petroleum (East China), Qingdao, China \\ ${ }^{2}$ Oilfield Chemicals R\&D Institute, COSL, Sanhe, China
}

\author{
Email address: \\ upcqiu@126.com (Tie Geng)
}

\section{To cite this article:}

Tie Geng, Zhengsong Qiu, Hailong Miao, Wei Zhang, Ke Lei. Performance Evaluation of Synthetic-Based Drilling Fluid with Flat Rheology. International Journal of Energy and Power Engineering. Vol. 7, No. 5, 2018, pp. 54-58. doi: 10.11648/j.ijepe.20180705.11

Received: October 12, 2018; Accepted: October 31, 2018; Published: November 19, 2018

\begin{abstract}
In offshore deepwater drilling, because of the low temperature aroud seafloor, the conventional synthetic-based drilling fluid becomes very thick, resulting in severe loss of drilling fluid during drilling through the deepwater formations with a narrow safe-density window. Therefore, it is important to improve the rheological properties of drilling fluid at deepwater drilling conditions. In this work, by investigating the effects of the key components including the base oil, emulsifier, wetting agent and rheology modifier on the rheological properties of synthetic-based drilling fluid at $4^{\circ} \mathrm{C}$ to $65^{\circ} \mathrm{C}$, the optimal additives were selected, and a synthetic-based drilling fluid with flat-rheology characteristics was developed. It was found that the gas-to-liquid oil had low viscosity at a low temperature, and was suitable for preparing deepwater drilling fluids. The evaluation experiments show that at $4^{\circ} \mathrm{C}$ to $65^{\circ} \mathrm{C}$, the drilling fluid could maintain stable yield point, 10 -min Gel and $6 \mathrm{r} /$ min reading value at a density of $0.9-1.5 \mathrm{~g} / \mathrm{cm}^{3}$ even after high temperature aging, while the rheological properties of the conventional synthetic-based drilling fluid were significantly influence by the low temperature. Moreover, it showed excellent performance in filtration reduction and shale inhibition, and could maintain good properties even being contaminated by seawater. Therefore, its stable rheological properties at the deepwater drilling temperature range can effectively control the equivalent circulating density, thus reducing the risk of drilling fluid loss during deepwater drilling.
\end{abstract}

Keywords: Flat-Rheology, Synthetic-Based Drilling Fluid, Deepwater Drilling, Low Temperature

\section{Introduction}

Offshore deepwater is very rich in oil and gas resources. During deepwater drilling, the low temperature of seabed shallow strata significantly affects the drilling fluid rheology [1]. Oil/synthetic-based drilling fluid has the advantages of a high penetration rate, wellbore stability, etc.; therefore, it is preferred for drilling in complex strata. However, this type of drilling fluid becomes very thick and even gelatinized in the low-temperature deepwater environment, thus increasing the equivalent circulating density (ECD). Because of a narrow safe-density window in deepwater formation, the high ECD will cause the loss of drilling fluid, thus severely affecting deepwater drilling operations and significantly increasing the cost of drilling fluid [2-5]. For the application of oil/synthetic-based drilling fluid in deepwater drilling, the concept of "flat rheology" has been proposed. It means that a relatively stable yield point as well as 10-min gel and $6 \mathrm{r} / \mathrm{min}$ reading (Ø6) of the drilling fluid in the deepwater wellbore are maintained in the temperature range $4.4-65^{\circ} \mathrm{C}$. Therefore, the ECD of drilling fluid can be effectively controlled, and the loss of drilling fluid can be reduced [6-8]. Some drilling services improved the key additives of rheology modifiers and emulsifiers by developing synthetic oils; the initially developed flat-rheology synthetic-based drilling fluid solved the problem [9-10] of controlling the rheological property of the oil/synthetic-based drilling fluid in deepwater drilling. However, the data shows that the rheological properties of the currently used flat-rheology synthetic-based drilling fluid in the temperature range $4-65^{\circ} \mathrm{C}$ changed by $30-50 \%$ or more, which may be further optimized. In this study, using gas-to-liquid oil as the base oil, the key components of the drilling fluid were investigated, and a synthetic-based drilling fluid with flat-rheology was developed. 


\section{Experimental Section}

The synthetic-based drilling fluid was rolled and aged at $100^{\circ} \mathrm{C}$ or $120^{\circ} \mathrm{C}$ for $16 \mathrm{~h}$. The aged drilling fluid was stirred at a high speed of 10,000 rpm for $30 \mathrm{~min}$ and then placed in a low-temperature thermostat bath. The rheological properties of the drilling fluid at temperatures of $4{ }^{\circ} \mathrm{C}-65^{\circ} \mathrm{C}$ were measured using a Fann 35 six-speed rotary viscometer [12]. The experiments for testing the shale cutting recovery rate, shale swelling rate, and filtrate loss were carried out following the methods reported in references [13-14]. To test the shale cutting recover rate, $50 \mathrm{~g}$ shale cuttings were screened with a 10 -mesh, and $350 \mathrm{~mL}$ test fluid were added to the roller oven cell. After hot rolling for $16 \mathrm{~h}$, the solution containing shale cuttings were screened with a 40 -mesh sieve. The remaining shale cuttings were washed and weighed, and the recovery rate was determined. To test the shale swelling rate, $10 \mathrm{~g}$ bentonite was compressed by a hydroform press at $15 \mathrm{MPa}$ for $5 \mathrm{~min}$ to produce a core sample. The sample was put onto a NP-02A linear swell meter and then soaked in a test fluid for $8 \mathrm{~h}$. The heights of the core sample before and after soaking were measured and the swelling rate can be obtained. The filtrate loss was measured by a ZNZ-D3 filtration apparatus under 0.7 $\mathrm{MPa}$ for $30 \mathrm{~min}$.

\section{Results and Discussions}

\subsection{Key Components of Flat-Rheology Synthetic-Based Drilling Fluid}

\subsubsection{Base Oil}

As the dispersing medium of a synthetic-based drilling fluid, the viscosity of the base oil directly affects the viscosity of the synthetic-based drilling fluid. When the other components of a drilling fluid are the same, the smaller the change in the viscosity of base oil with temperature, the more stable the rheological properties of the synthetic-based drilling fluid. The viscosity trends of different base oils in a temperature range in a typical deepwater drilling wellbore were observed experimentally. Figure 1 shows that the viscosities of all the base oils increased with the decrease in temperature, but to different extents. The viscosities of the mineral oil and diesel were higher than the synthetic oil, which was a kind of gas-to-liquid oil, especially at a low temperature. In comparison, the viscosity of the gas-to-liquid oil is low, and was not significantly increased at a low temperature. Therefore, it is suitable for developing a flat-rheology synthetic-based drilling fluid.

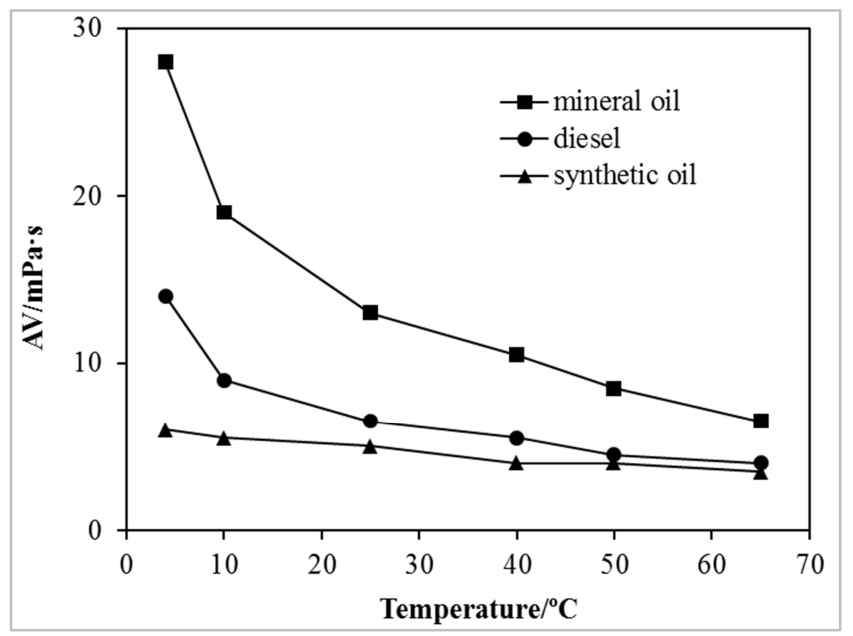

Figure 1. Viscosity trends of different base oils with temperature.

\subsubsection{Emulsifier and Wetting Agent}

The emulsifier and wetting agent are the key component of non-aqueous drilling fluid for maintaining the stability of the emulsion. The optimal combination of emulsifier and wetting agent were selected based on lots of experiments. The results in Table 1 show that the combination of $3 \%$ emulsifier and $1 \%$ wetting agent provided stable rheological properties for the drilling fluid. The YP maintained in the range of 7-8 Pa, and the emulsion-breaking voltage was $534 \mathrm{~V}$, indicating that the drilling fluid has good rheological property and stability. Therefore, they were selected as the emulsifier and wetting agent for the flat-rheology synthetic-based drilling fluid.

Table 1. Effect of emulsifier and wetting agent on rheological properties of drilling fluid.

\begin{tabular}{|c|c|c|c|c|c|}
\hline Agent & Temperature $\left({ }^{\circ} \mathrm{C}\right)$ & $\mathrm{AV}(\mathrm{mPa} \cdot \mathrm{s})$ & $\mathrm{PV}(\mathrm{mPa} \cdot \mathrm{s})$ & YP (Pa) & $\operatorname{ES}(\mathrm{V})$ \\
\hline \multirow{3}{*}{ \#1 Emulsifier and wetting agent } & 4 & 58 & 49 & 9 & \multirow{3}{*}{225} \\
\hline & 25 & 33 & 28 & 5 & \\
\hline & 65.5 & 16 & 14 & 2 & \\
\hline \multirow{3}{*}{ \#2 Emulsifier and wetting agent } & 4 & 54 & 46 & 8 & \multirow{3}{*}{534} \\
\hline & 25 & 33 & 26 & 7 & \\
\hline & 65.5 & 21 & 14 & 7 & \\
\hline \multirow{3}{*}{ \#3 Emulsifier and wetting agent } & 4 & 59 & 50 & 9 & \multirow{3}{*}{413} \\
\hline & 25 & 38 & 32 & 6 & \\
\hline & 65.5 & 22 & 19 & 3 & \\
\hline
\end{tabular}

\subsubsection{Rheology Modifier}

Rheology modifier is a key component for controlling the rheological properties of a synthetic-based drilling fluid. Selection of an appropriate rheology modifier is very important to achieve the "flat rheology" characteristics of a synthetic-based drilling fluid. Using polybasic carboxylic acid, Fatty acid methyl ester, and polyene polyamine, a new type of rheology modifier was synthesized. The effect of the rheology modifier on the rheological properties of synthetic-based drilling fluid was tested. Table 2 shows that the effect of temperature on the rheological properties of the drilling fluid 
was not significant in the presence of the $1 \mathrm{wt} \%$ rheology modifier. The YP was $8.5-11 \mathrm{~Pa}$ at $4^{\circ} \mathrm{C}$ to $65^{\circ} \mathrm{C}$, and the $\varnothing 6$ value was $10-13$. Moreover, the drilling fluid containing the new rheology modifier has good filtration property. The filtrate loss at high temperature $\left(120^{\circ} \mathrm{C}\right)$ and high pressure $(3.5$ $\mathrm{MPa}$ ) is $4.0 \mathrm{~mL}$. The emulsion-breaking voltage is higher than $500 \mathrm{mV}$ at different temperature, indicating that the synthetic-based drilling fluid has good stability.

Table 2. Effect of rheology modifier on rheological properties of synthetic-based drilling fluid.

\begin{tabular}{lllll}
\hline Temperature $\left({ }^{\circ} \mathbf{C}\right)$ & AV (mPa.s) & PV (mPa.s) & YP (pa) & Ø6 \\
\hline 4 & 70 & 59 & 11 & 10 \\
25 & 48.5 & 39 & 9.5 & 10 \\
30 & 44.5 & 36 & 8.5 & 10 \\
40 & 38 & 29 & 9 & 11 \\
50 & 34 & 24 & 10 & 12 \\
65 & 28 & 18 & 10 & 13 \\
\hline
\end{tabular}

The long-chain alkyl group of the rheology modifier dissolved in the oil phase and adsorbed on the surface of the organic clay. The polar groups closely connected the organic clay and emulsified water droplets together by electrostatic attraction or hydrogen-bonding interactions with emulsified water droplets, resulting in the formation of a network structure. The three-dimensional network structure was also formed among the polymer molecules by binding or hydrogen-bonding interactions. Therefore, a strong grid structure was formed in the system, representing the increase in the yield point of drilling fluid from a macroscopic aspect and helping to carry the cuttings and preventing the settlement of weighting agents.

\subsection{Performance Evaluation of the Synthetic-Based Drilling Fluid}

The formula was experimentally optimized for the synthetic-based drilling fluid with flat rheological property, as shown in Table 3.

Table 3. Composition of the synthetic-based drilling fluid with flat rheology.

\begin{tabular}{ll}
\hline Component & Concentration (wt \%) \\
\hline Synthetic oil & $70-85$ \\
Emulsifier & $3 \%$ \\
Wetting agent & $1 \%$ \\
Rheology modifier & $1 \%$ \\
25 wt \% CaCl2 solution & $15-30$ \\
Organic clay & $2 \%$ \\
CaO & $2 \%$ \\
Filtrate reducer & $3 \%$ \\
Weighting agent & Depend on the density \\
\hline
\end{tabular}

\subsubsection{Evaluation of Rheological Properties and Filtration}

Synthetic-based drilling fluids with different densities were prepared, and the rheological and filtration properties of the drilling fluid after hot rolling at $100^{\circ} \mathrm{C}$ and $120^{\circ} \mathrm{C}$ for $16 \mathrm{~h}$ were investigated experimentally. The results are shown in Table 4. The yield point, 10-min gel, and Ø6 value of the developed drilling fluid was stable in the wellbore temperature range $4-65^{\circ} \mathrm{C}$, and it had the "flat-rheology" characteristics [8]. In addition, the drilling fluid had an excellent effect of filtration reduction, and the filtration loss was 3.2 and $3.8 \mathrm{~mL}$ at $100^{\circ} \mathrm{C}$ and $120^{\circ} \mathrm{C}$ respectively, and the emulsion breaking voltage was higher than $500 \mathrm{~V}$. Therefore, this drilling fluid has flat rheology and good stability at $4-65^{\circ} \mathrm{C}$ after high temperature aging, and it can be used in field application when the downhole temperature is high.

Table 4. Rheological and filtration properties of the drilling fluid after hot rolling.

\begin{tabular}{|c|c|c|c|c|c|c|c|c|}
\hline Rolling temperature $\left({ }^{\circ} \mathrm{C}\right)$ & Temperature $\left({ }^{\circ} \mathrm{C}\right)$ & $\mathbf{A V}(\mathbf{m P a} \cdot \mathbf{s})$ & PV $(\mathrm{mPa} \cdot \mathrm{s})$ & $\mathbf{Y P}(\mathbf{P a})$ & $\varnothing 6$ & 10-min Gel (Pa) & Filtration loss (mL) & ES (V) \\
\hline \multirow{4}{*}{120} & 4 & 68.5 & 60 & 8.5 & 8 & 12.5 & \multirow{4}{*}{3.8} & \multirow{4}{*}{630} \\
\hline & 25 & 35 & 28 & 7 & 8 & 12 & & \\
\hline & 50 & 28.5 & 21 & 7.5 & 8 & 11.5 & & \\
\hline & 65 & 24 & 16 & 8 & 9 & 12 & & \\
\hline \multirow{3}{*}{100} & 4 & 64.5 & 54 & 10.5 & 8.5 & 11.5 & \multirow{3}{*}{3.2} & \multirow{3}{*}{658} \\
\hline & 25 & 43 & 34 & 9 & 8 & 12 & & \\
\hline & 50 & 32 & 22 & 10 & 10 & 12.5 & & \\
\hline
\end{tabular}

The rheological properties of the drilling fluid at different densities were further tested. Table 5 shows that the drilling fluid could still maintain stable yield point, $\varnothing 6$ value and $10-\mathrm{min}$ Gel at a density of $0.9-1.5 \mathrm{~g} / \mathrm{cm}^{3}$. The low temperature did not significantly impact the rheological parameters. The filtration loss was smaller than $5 \mathrm{~mL}$, and the emulsion-breaking voltage was higher than $400 \mathrm{~V}$, indicating that the drilling fluid has good filtration property and stability at different densities.

Table 5. Rheological and filtration properties of synthetic-based drilling fluid with different densities.

\begin{tabular}{|c|c|c|c|c|c|c|c|c|}
\hline Density $\left(\mathrm{g} \cdot \mathrm{cm}^{-3}\right)$ & Temperature $\left({ }^{\circ} \mathrm{C}\right)$ & $\mathrm{AV}(\mathrm{mPa} \cdot \mathbf{s})$ & PV (mPa·s) & YP (Pa) & 06 & 10-min Gel (Pa) & Filtration loss $(\mathrm{mL})$ & ES (V) \\
\hline \multirow{3}{*}{0.9} & 4 & 34 & 27 & 7 & 8 & 11 & \multirow{3}{*}{4.4} & \multirow{3}{*}{624} \\
\hline & 25 & 23 & 17 & 6 & 9 & 10 & & \\
\hline & 65 & 15.5 & 9 & 6.5 & 10 & 10.5 & & \\
\hline \multirow{3}{*}{1.2} & 4 & 68.5 & 60 & 8.5 & 8 & 10.5 & \multirow{3}{*}{4.8} & \multirow{3}{*}{630} \\
\hline & 25 & 35 & 28 & 7 & 8 & 11 & & \\
\hline & 65 & 24 & 16 & 8 & 9 & 12 & & \\
\hline \multirow{2}{*}{1.5} & 4 & 97 & 86 & 11 & 10 & 12 & \multirow{2}{*}{5.2} & \multirow{2}{*}{491} \\
\hline & 65 & 31 & 22 & 9 & 12 & 12.5 & & \\
\hline
\end{tabular}




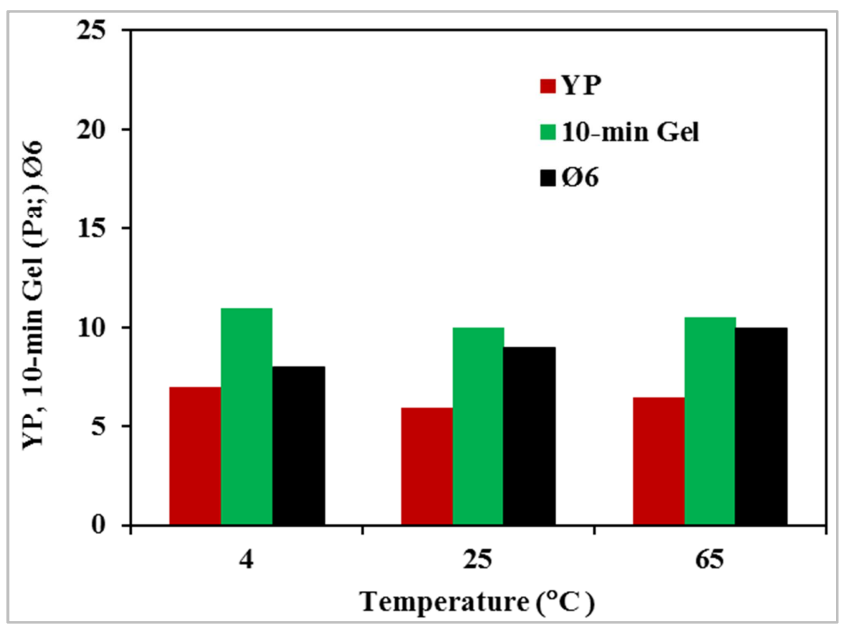

(a) Flat rheology drilling fluid

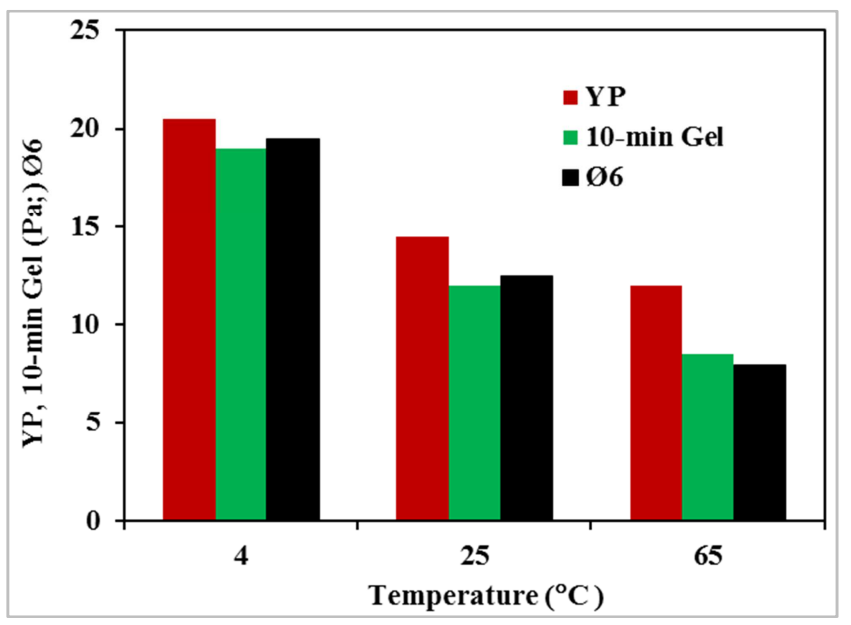

(b) Conventional drilling fluid

Figure 2. Comparison of rheological properties of synthetic-based drilling fluids.

To better characterize the "flat rheology" characteristics of the synthetic-based drilling fluid, the rheological properties of the drilling fluid with a density of $1.2 \mathrm{~g} / \mathrm{cm}^{3}$ and those of the conventional synthetic-based drilling fluid were compared. The results are shown in Figure 2. By comparison, the rheological properties of the conventional synthetic-based drilling fluid were significantly affected by the temperature. The significant increase in the yield point, 10-min gel, and Ø6 value of the conventional synthetic-based drilling fluid at a low temperature causes problems of exceedingly high ECD and excessively large surge pressure. The flat-rheology synthetic-based drilling fluid showed a moderate yield point, 10 -min gel, and Ø6 value. Its rheological properties stabilized in the temperature range $4-65^{\circ} \mathrm{C}$ and helped to the control of the ECD of drilling fluid.

\subsubsection{Evaluation of Shale Inhibition Property}

The experimental results of the shale cuttings dispersion tests shows that the recovery rate of shale cuttings in the water was $10.9 \%$, while the recovery rate in the synthetic-based drilling fluid was up to $92.0 \%$. The swelling rate of shale core was $22.0 \%$ in water, while that in the drilling fluid was only $1.4 \%$. Therefore, the drilling fluid had an excellent effect on inhibiting the shale hydration dispersion and swelling, thus effectively stabilizing the wellbore.

\subsubsection{Evaluation of Contamination Resistance to Seawater}

The invasion of seawater into the synthetic-based drilling fluid will significantly influence the stability and properties of synthetic-based drilling fluid because they can break the emulsion. Therefore, the contamination resistance of the drilling fluid to seawater was tested. Table 6 shows that after the addition of $5 \%$ seawater, the drilling fluid could still maintain good rheological and filtration properties, and the emulsion-breaking voltage was higher than $400 \mathrm{~V}$, indicating its good contamination resistance to seawater. Therefore, in drilling operations, it can maintain stable properties even being contaminated by seawater.

Table 6. Properties of the synthetic-based drilling fluid after the addition of $5 \%$ seawater.

\begin{tabular}{|c|c|c|c|c|c|c|c|}
\hline Temperature $\left({ }^{\circ} \mathrm{C}\right)$ & $\mathrm{AV}(\mathrm{mPa} \cdot \mathrm{s})$ & PV $(\mathrm{mPa} \cdot \mathrm{s})$ & $\mathbf{Y P}(\mathbf{P a})$ & 06 & 10-min Gel (Pa) & Filtration loss (mL) & $\operatorname{ES}(\mathbf{V})$ \\
\hline 4 & 73 & 64 & 9 & 8 & 11 & & \\
\hline 25 & 34 & 26 & 8 & 9 & 10 & 4.4 & 487 \\
\hline 65 & 26 & 17 & 9 & 10 & 10.5 & & \\
\hline
\end{tabular}

\section{Conclusions}

Based on the investigation of the key components including the base oil, emulsifier, wetting agent and rheology modifier, a synthetic-based drilling fluid with flat-rheology characteristics was developed. At $4^{\circ} \mathrm{C}$ to $65^{\circ} \mathrm{C}$, it can maintain stable yield point, 10-min Gel and Ø6 value at a density of $0.9-1.5 \mathrm{~g} / \mathrm{cm}^{3}$. A comparison with the conventional synthetic-based drilling fluid showed that the effect of low temperature on the rheological properties of the synthetic-based drilling fluid was minor, while the effect on the conventional synthetic-based drilling fluid was very significant. Moreover, it showed excellent performance in filtration reduction and shale inhibition, and it can still have good properties even being contaminated by seawater. Therefore, it is suitable for offshore deepwater drilling operations.

\section{References}

[1] Zhao X, Qiu Z, Huang W, et al. Mechanism and method for controlling low-temperature rheology of water-based drilling fluids in deepwater drilling. Journal of Petroleum Science and Engineering, 2017, 154: 405-416. 
[2] Davison J M, Clary S, Saasen A, et al. Rheology of various drilling fluid systems under deepwater drilling conditions and the importance of accurate predictions of downhole fluid hydraulics. SPE 56632. SPE Annual Technical Conference and Exhibition, 3-6 October, Houston, Texas, USA, 1999.

[3] Zamora M, Broussard P N, Stephens M P. The top 10 mud-related concerns in deepwater drilling operations. SPE 59019. SPE International Petroleum Conference and Exhibition in Mexico, 1-3 February, Villahermosa, Mexico, 2000.

[4] Herzhaft B, Peysson Y, Isambourg P, et al. Rheological properties of drilling muds in deep offshore conditions. SPE/IADC 67736. SPE/IADC Drilling Conference, 27 February-1 March, Amsterdam, Netherlands, 2001.

[5] Dokhani V, Ma Y, Yu M. Determination of equivalent circulating density of drilling fluids in deepwater drilling. Journal of Natural Gas Science and Engineering, 2016, 34, 1096-1105.

[6] Van Oort E, Lee J, Friedheim J, et al. New flat-rheology synthetic-based mud for improved deepwater drilling. SPE 90987, 2004

[7] Rojas J C, Bern P, Plutt L J, et al. New constant-rheology synthetic-based fluid reduces downhole losses in deepwater environments. SPE 109586. SPE Annual Technical Conference and Exhibition, 26-29 September, Houston, Texas, USA, 2007.
[8] Knox D, Bulgachev R, Cameron I. Defining Fragile-The Challenge of Engineering Drilling Fluids for Narrow ECD Windows. SPE/IADC 173059. SPE/IADC Drilling Conference and Exhibition, 17-19 March, London, England, UK, 2015.

[9] Schlemmer R, Phoon G, Lumpur K. A new generation associative polymer extends temperature stability of deepwater drilling fluid. IPTC 15383. International Petroleum Technology Conference, 15-17 November, Bangkok, Thailand, 2011.

[10] Young S, Friedheim J, John Lee, et al. A new generation of flat rheology invert drilling fluids. SPE 154682. SPE Oil and Gas India Conference and Exhibition, 28-30 March, Mumbai, India, 2012.

[11] Huang W, Leong Y K, Chen T, et al. Surface chemistry and rheological properties of API bentonite drilling fluid: $\mathrm{pH}$ effect, yield stress, zeta potential and ageing behaviour. J. Petro. Sci. Eng. 2016, 146, 561-569.

[12] Zhao X, Qiu Z, Xu J, et al. Flat-rheology oil-based drilling fluid for deepwater drilling. International Journal of Heat and Technology, 2017, 35(1): 19-24.

[13] Zhong H, Qiu Z, Huang W, et al. Bis (hexamethylene) triamine as potential shale inhibitor in water-based drilling fluid. Open Petroleum Engineering Journal, 2013, 6(1), 49-56.

[14] Zhong H, Sun D, Huang W, et al. Effect of cycloaliphatic amine on the shale inhibitive properties of water-based drilling fluid. The Open Fuels \& Energy Science Journal, 2015, 8, 19-27. 